\title{
Influence of different excipients on the properties of hard gelatin capsules with metamizole sodium
}

\author{
Magdalena Rogowska $^{1 *}$, Karol Iwaniak ${ }^{1}$, Andrzej Polski ${ }^{1}$, Karolina Slawinska $^{1}$, \\ Karolina Sobotka-Polska ${ }^{2}$, Joanna Modrzewska ${ }^{1}$, Ewa PoleszaK ${ }^{1}$
}

${ }^{1}$ Chair and Department of Applied Pharmacy, Medical University of Lublin, 1 Chodzki, 20-093 Lublin, Poland

${ }^{2}$ Department of Organic Chemistry, Medical University of Lublin, Poland

\section{ARTICLE INFO}

Received 08 March 2016

Accepted 31 March 2016

\section{Keywords:}

release study,

metamizole sodium, capsules.

\begin{abstract}
Metamizole is an effective non-opioid analgesic drug used in the treatment of acute and chronic pain. Due to induced potentially life-threatening blood disorders, metamizole was withdrawn from market in many parts of the world, however, it is one of the most popular analgesics in Poland that is available as an over the counter drug. Patients tend to prefer capsules over tablets, as they are easier to swallow and taste better. The powderfilled capsules also have greater bioavailability and require less excipients, as compared to tablets. Polymic excipients are mainly used in capsule filling, and have influence upon the physico-chemical properties of the hard gelatin capsules and the powder formulation. The aim of the study was to determine whether various combinations of polymers impact the disintegration time and pharmaceutical availability of hard gelatin capsules with metamizole sodium. The results of our work demonstrated that the $80 \%$ of all active substance was released in all tested formulations within 15 minutes. Herein, the capsule containing lactose monohydrate had the longest release ( $4 \%$ after $2 \mathrm{~min}$.), while capsules containing mannitol had the fastest release ( $81.2 \%$ after 2 min.). Moreover, the addition of HPMC to capsules with lactose brought about a slight increase in the metamizole release rate, while the addition of PVP 30 to capsules with microcrystalline cellulose slightly accelerated release. This data suggests that the use of different polymers in capsules formulation brings about changes in the physical properties of powders and modifies the release profile of metamizole. In our study, the most preferred formulation was one containing microcrystalline cellulose (good powder properties and fairly fast release).
\end{abstract}

\section{INTRODUCTION}

Metamizole (dipyrone) is a one of the strongest non-opioid analgesic drugs. As a non-steroidal anti-inflammatory drug (a NSAID), it can be used to treat many different types and intensity of pains, as well as when other forms of treatment are ineffective $[12,15]$. Metamizole was withdrawn from the market in several countries (such as the USA, the UK, Sweden, Japan) or has been restricted to being made available only with a medicine prescription [5]. This is because of widely differing estimates of it bringing about potential risks of life-threatening blood disorders such as agranulocytosis [9]. In Poland, metamizole is one of the most often used analgesic drugs and is a common non-prescription over the counter product [2].

\footnotetext{
* Corresponding author

e-mail: magda.nalesniak@umlub.pl
}

The pharmaceutical market offers many forms of drugs containing metamizole, and the most commonly used are solid oral dosage forms such as tablets and capsules [17]. The capsule is devoid of an unpleasant taste or odor because the medication is closed into the capsule shell. In addition, patients confirm that capsules are easier to swallow than tablets [19]. Hard gelatin capsules enhance absorption, and have influence upon the bioavailability parameters of the drug. Moreover, powder-filled capsules have greater bioavailability than tablets, because the gelatin shells dissolves rapidly, whereas the tablets must first disintegrate $[3,11]$. The capsule content may be a drug substance with suitable excipients. These should neither exert any pharmacological action, nor adversely affect the stability of the dosage form or the bioavailability of the drug [7]. Only one to four excipients are needed to prepare 
gelatin capsules, as compared to tablets [23]. In capsule preparation, magnesium stearate is a widely used lubricant and can improve flow properties, when added in small quantities [8], while mannitol is a widely used compound for orodispersible tablets [4].

Polymeric compounds are an important and diverse group of excipients used in the drug formulation. They can be either natural, semisynthetic or synthetic, and can be divided into several groups; many of which may perform more than one function [24]. Several studies have shown that polymers influence the physico-chemical properties of the active substance in the capsule formulation [10]. Furthermore, they can delay the release rate of a drug from a capsule, as the rate of release depends on the amount and the molecular weight of a polymer contained in the formulation [6]. The most commonly used capsule fillers are starch and microcrystalline cellulose (MCC). The latter can also be used as a disintegrant [20].Pregelatinized starch may be used to improve flowability [1], whereas polyvinylpyrrolidone is mainly used as a binder which significantly increases the hardness and strength of solid dosage forms [25]. Hydroxypropylmethylcellulose is also used as a binder and release delaying agent [18], while croscarmellose sodium is widely used in pharmaceutical formulations as a superdisintegrant [16]. It should be noted that the degree of polymerization of cellulose materials influences some powder properties [22]. Silicified MCC is produced by co-processing of $98 \%$ microcrystalline cellulose and $2 \%$ fumed silica, yielding improved flowability and packing properties [14].

The release of the therapeutic drug into the surrounding body fluids is crucial for the effectiveness of therapy, as only when such a substance is released from the dosage form can it dissolve and be absorbed and exert its pharmacological activity. The rate and extent of release of the active substance depends primarily on the dosage form, and the process of release is also affected by the method of drug preparation. This fact can be used to modify the release of the active substance from the drug. The present work is a study of the effect of different polymers on the properties of hard gelatin capsules, and on a powder formulation comprising a model substance (Metamizol sodium). Its aim was to determine whether different combinations of polymers affect the disintegration time and availability of pharmaceutical hard gelatin capsules containing metamizole sodium. The data obtained are a significant contribution to the study of the drug.

\section{MATERIALS AND METHODS}

\section{Materials}

Metamizole sodium (MET) was purchased from Pharma Cosmetic Kraków (Poland). Polyvinylpyrrolidone K30 (PVP30) and hydroxypropylmethylcellulose (HPMC) were all obtained from Sigma-Aldrich Chemmie $\mathrm{GmbH}$ (USA). Mannitol (M), lactose monohydrate and magnesium stearate (MS) were manufactured by POCH S.A. (Poland). Croscarmellose sodium (VIVASOL) and microcrystalline cellulose (VIVAPUR 102) were provided by JRS Pharma Gmbh \& CO KG (Germany). Fumed silica (AEROSIL 200) was a Evonik (Germany) product. Pregelatinized maize starch (CPharmGel) was purchased from Cargill Benelux BV (Netherlands). Talc was purchased from PZF "Cefarm Lublin" S.A. (Poland). All other reagents used in the experiments, were of analytical grade. Distilled water was freshly prepared.

\section{Methods}

\section{Preparation of hard gelatin capsules with metamizole sodium}

Six series of capsules were prepared by filling hard gelatin capsules size 00 (Capsugel-Bornem, Belgium) with a powder containing metamizole sodium $(40 \%)$ and various excipients. Powder formulations for each series (Tab. 1) were obtained by weighting and mixing components. Powder was used for manufacturing 100 capsules with a capacity filling of $625 \mathrm{mg}$. The hard gelatin capsules were filled by way of utilizing a manual capsule filling machine (Capsunorm ${ }^{\circledR}$ 00/100, Eprus, Poland). The machine was cleaned to remove adhering powder particles before dispensing the next series of capsules.

Table 1. Composition of MET capsules at $625 \mathrm{mg}$ weight

\begin{tabular}{|l|c|c|c|c|c|c|}
\hline \multirow{2}{*}{$\begin{array}{c}\text { Formulation } \\
\text { ingredients (\%) }\end{array}$} & \multicolumn{7}{|c|}{ Formula } \\
\cline { 2 - 7 } & $\mathrm{C} 6$ & $\mathrm{C} 2$ & $\mathrm{C} 5$ & $\mathrm{C} 1$ & $\mathrm{C} 3$ & $\mathrm{C} 4$ \\
\hline MET & 40 & 40 & 40 & 40 & 40 & 40 \\
\hline Mannitol & 56 & - & - & - & - & - \\
\hline Vivapur 102 & - & 47 & 53 & - & - & - \\
\hline Lactose & - & - & - & 49 & 58 & 54 \\
\hline PVP 30 & - & 10 & - & - & - & - \\
\hline HPMC & - & - & - & 10 & - & - \\
\hline Vivasol & - & - & 5 & - & - & - \\
\hline Cpharm Gel & - & - & - & - & - & 5 \\
\hline Talc & 3 & 3 & - & - & - & - \\
\hline Aerosil 200 & 1 & - & 1 & - & 1 & - \\
\hline Magnesium stearate & - & - & 1 & 1 & 1 & 1 \\
\hline
\end{tabular}

\section{Physical properties of powder formulation}

Flow rate, mass flow rate, volume flow rate and angle of repose of powders were assessed by using the granules and powder flow tester (Erweka type GTB, Germany), in accordance with the requirements of the European Pharmacopoeia. Particle size distribution of the powders was studied by a sieve analysis. After mixing the powder in the vibratory sieve shaker AS 200 basic (Retsch, Germany), the mass and the share of each fraction in the powder batch were determined. The measurements of tap density and bulk density were performed using the tapped density tester (Erweka, type SVM 222, Germany). The Hausner ratio was then calculated [7].

\section{Analysis of Weight Uniformity}

Capsule filling weight uniformity was determined by randomly selecting 20 capsules from each batch. Powder formulation from the capsules were sampled and accurately weighted individually using an analytical balance (Mettler AT 201, Switzerland). The results were shown as mean 
values of 20 determinations in each batch. The calculations of average weight of powders were used to determine standard deviation [7].

\section{Analysis of Disintegration Time}

Six capsules from each batch were selected and put into vessels of the disintegration tester (Erweka Type ZT 222, Germany). Water at $37^{\circ} \mathrm{C} \pm 0.5^{\circ} \mathrm{C}$ was used as medium. The disintegration time was recorded until capsules opened and the fillers were released [7].

\section{Pharmaceutical availability of hard gelatin capsules with metamizole sodium}

\section{Calibration curve}

A stock solution of dipyrone was obtained by dissolving $10 \mathrm{mg}$ of metamizole sodium in $0.1 \mathrm{M} \mathrm{HCI}$. The working solutions were prepared from the stock solution $(0.1 \mathrm{ug} / \mathrm{ml})$ following dilution with $0.1 \mathrm{M} \mathrm{HCI}$. Appropriate aliquots of metamizole sodium were transferred into a series of $10 \mathrm{ml}$ measuring flasks and adjusted to volume with 0.1 M HCI. Each solution (containing metamizole sodium at concentration of $2.5 ; 5 ; 10 ; 15 ; 20 ; 30 \mathrm{ug} / \mathrm{ml}$ ) was placed in a cuvette and the absorbance of each standard was measured at $258 \mathrm{~nm}$, using a Helios Omega UV-VIS spectrophotometer (Thermo Scientific, USA). The maximum absorbance was determined by the previous preparation of the absorption spectrum of metamizole sodium against 0.1 M HCI as a blank over the range of 200-600 nm. Standard solutions were used in order to plot a calibration curve. The corresponding regression equation $(\mathrm{y}=0.256 \mathrm{x})$ was developed and correlation coefficient $\left(\mathrm{R}^{2}=0.9981\right)$ was computed.

\section{Release profile}

The dissolution test of hard gelatin capsules with metamizole sodium was carried out in the basket apparatus (Erweka, Germany), by way of employing $900 \mathrm{ml}$ of $0.1 \mathrm{M}$ $\mathrm{HCI}$ maintained at $37^{\circ} \mathrm{C} \pm 0.5^{\circ} \mathrm{C}$. Each capsule was placed in each of the six vessels of the basket apparatus at a fixed rotation speed of $100 \mathrm{rpm}$. Samples of $2 \mathrm{ml}$ were withdrawn from the apparatus at $2 ; 5 ; 10 ; 15 ; 30$ and 45 minutes. The volume in the vessel was immediately replaced with fresh dissolution medium maintained at the same temperature. The obtained aliquots were further diluted by adding $3 \mathrm{ml}$ of $0.1 \mathrm{M} \mathrm{HCI}$. The absorbance at $258 \mathrm{~nm}$ was measured. The amount of the released substance was determined from the calibration curve made from standards according to current Pharmacopoeia [7].

\section{Statistical analysis}

A Student t-test for two samples was performed to compare the difference of the dissolution profile of the tablets containing microcrystalline or lactose with different excipients. A value of $\mathrm{p}<0.05$ was considered significant.

\section{RESULTS AND DISCUSSION}

The powder properties are summarized in table 2 . The angle of repose is a traditional characterization method
Table 2. Characteristics of powder formulations

\begin{tabular}{|l|c|c|c|c|c|c|}
\hline \multirow{2}{*}{ Powder properties } & \multicolumn{6}{|c|}{ Powder formula } \\
\cline { 2 - 7 } & C6 & C2 & C5 & C1 & C3 & C4 \\
\hline Angle of repose $\left({ }^{\circ}\right)$ & 46.10 & 44.6 & 39.07 & 47.95 & 45.57 & 46.70 \\
\hline Flow rate $(\mathrm{s} / 100 \mathrm{~g})$ & 4.50 & 4.87 & 7.50 & 5.43 & 3.20 & 3.83 \\
\hline $\begin{array}{l}\text { Volume flow rate } \\
(\mathrm{s} / 100 \mathrm{ml})\end{array}$ & 1.80 & 2.10 & 2.40 & 2.20 & 1.80 & 2.30 \\
\hline Mass flow rate $(\mathrm{g} / \mathrm{s})$ & 47.60 & 22.77 & 9.90 & 6.90 & 30.73 & 46.33 \\
\hline Hausner ratio & 1.46 & 1.47 & 1.41 & 1.31 & 1.50 & 1.42 \\
\hline X50 $(\mu \mathrm{m})$ & 0.090 & 0.125 & 0.090 & 0.090 & 0.090 & 0.125 \\
\hline
\end{tabular}

for pharmaceutical powder flowability. Herein, lower values of the angle of repose indicate better flowability [21]. The powder containing microcrystalline cellulose had the lowest value of the angle of repose (C3: $39.1^{\circ}$ good flow; $\mathrm{C} 2$ : $44.6^{\circ}$ sufficient). The other four formulas had higher values of the angle of repose ( $>45^{\circ}$ poor flow). In the case of lactose, the flowability was worse, because of moisture content increase in the powder. The celluloses showed the opposite effect as compared to lactose [22]. Of the tested materials, only formulation $\mathrm{C} 3$ possessed satisfactory flow properties. The Hausner ratio for some tested powders was either considered sufficient $(\mathrm{C} 2: 1.34 ; \mathrm{C} 3: 1.26)$ or, for the other powders, poor $(>1.35)$. A sieve analysis of powders showed that $50 \%$ of all particles in the analyzed powders did not exceed $0.090 \mu \mathrm{m}$ for C1, C3, C4, C5 and $<0.125 \mu \mathrm{m}$ in C2 and C6. Values of flow rate (3.2-7.5 s/100 g) and volume flow rate $(1.8-2.4 \mathrm{~s} / 100 \mathrm{ml})$ were similar for all powders. The powder from the $\mathrm{C} 4$ and $\mathrm{C} 3$ capsules showed the lowest values of mass flow rate ( 6.9 and $9.9 \mathrm{~g} / \mathrm{s}$, respectively), whereas, powders $\mathrm{C} 6$ and $\mathrm{C} 1$ exhibited the highest values $(46.3 \mathrm{~g} / \mathrm{s}$ and $47.6 \mathrm{~g} / \mathrm{s}$, respectively). The addition of MCC and fumed silica yielded the best powder properties.

The physical properties of capsules are shown in table 3. Deviations from the average weight of capsules met the pharmacopoeial requirements $( \pm 7.5 \%)$. Disintegration time of capsules ranged from $1 \mathrm{~min}(\mathrm{C} 4)$ to $1 \mathrm{~min} 45 \mathrm{~s}$ (C5 and C6).

Table 3. Physical properties of capsules

\begin{tabular}{|l|c|c|c|c|c|c|}
\hline \multirow{2}{*}{\multicolumn{1}{|c|}{ Test }} & \multicolumn{7}{|c|}{ Formula } \\
\cline { 2 - 7 } & $\mathrm{C} 6$ & $\mathrm{C} 2$ & $\mathrm{C} 5$ & $\mathrm{C} 1$ & $\mathrm{C} 3$ & $\mathrm{C} 4$ \\
\hline $\begin{array}{l}\text { Mean weight } \\
\left. \pm \% \text { deviation }^{\mathrm{a}} \mathrm{g}\right)\end{array}$ & $\begin{array}{l}0.597 \\
\pm 5.2\end{array}$ & $\begin{array}{l}0.450 \\
\pm 4.4\end{array}$ & $\begin{array}{l}0.476 \\
\pm 4.6\end{array}$ & $\begin{array}{c}0.512 \\
\pm 3.9\end{array}$ & $\begin{array}{l}0.494 \\
\pm 6.4\end{array}$ & $\begin{array}{c}0.571 \\
\pm 6.8\end{array}$ \\
\hline $\begin{array}{l}\text { Disintegration time } \\
\text { (min:s) }\end{array}$ & $1: 30$ & $1: 30$ & $1: 30$ & $1: 00$ & $1: 45$ & $1: 45$ \\
\hline
\end{tabular}

The dissolution profiles are shown in figure 1. More than the $80 \%$ of all active substance was released within 15 minutes for all tested formulations (96.73-102.52\%). Herein, the capsules containing mannitol (C1) had the fastest release, while capsules containing lactose and Cpharm Gel (C6) showed the longest one (respectively, $81.2 \%$ and $4 \%$ after the first 2 minutes). In our study, formulations containing MCC showed faster release (C2, C3), whereas, tablets with MCC showed good release properties [13]. The differences between release rates for the tablets with different excipients were tested after 2 minutes. In this part of the study, on one hand, replacement of Cpharm Gel with lactose in capsules delayed the release, while the addition of HPMC to capsules 
with lactose brought about an increase in the release rate. On the other hand, replacement of PVP 30 with MCC accelerated the release. After 2 minutes testing, the differences between the dissolution rate of the tablets that contained $58 \%$ lactose and those prepared by using $49 \%$ lactose and $10 \%$ HPMC or tablets that contained $47 \%$ MCC and $10 \%$ PVP30 and those prepared by using 53\% MCC and 5\% croscarmellose sodium, were significant $(\mathrm{p}>0.05)$.

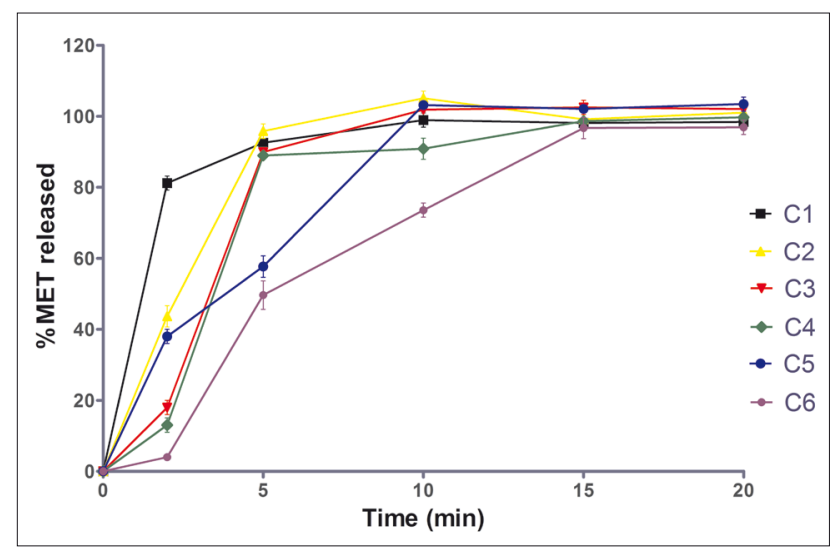

Figure 1. Mean dissolution profiles of MET from capsules C1-C6 (mean values $\mathrm{n}=6, \pm \mathrm{SD}, \mathrm{p}>0.05$ )

\section{CONCLUSIONS}

Our work demonstrates that the use of different excipients (such as MCC, lactose and mannitol) substantially changed the physical properties of the studied powders, as well as the MET release profile from the prepared capsules. Herein, the replacement of some excipients by polymeric excipients such as Cpharm Gel, HPMC and PVP 30, slightly increased the MET release rate. Moreover, capsules containing lactose exhibited the slowest MET release rate, while the capsules containing mannitol showed the fastest release rate of MET. Our study reveals that, in regard to powder properties and release rate, capsules containing MCC with fumed silica and croscarmellose sodium were of preference.

\section{REFERENCES}

1. Augsburger L.L. (1996). Hard and soft gelatin capsules. In: Modern Pharmaceutics, 3rd ed. Banker G.S., Rhodes C.T. (editors). New York: Marcel Dekker, Inc.; p. 395.

2. Basak G.W., Drozd-Sokołowska J., Wiktor-Jedrzejczak W.: Update on the incidence of metamizole sodium-induced blood dyscrasias in Poland. J. Int. Med. Res., 38(4), 1374, 2010.

3. Bowman B.J., Ofner III C.M. (2002). Hard gelatin capsules. In: Protein-Based Films and Coatings. Gennadios A. (editor). Boca Raton: CRC Press; p.367.

4. Daraghmeh N. et al.: Co-processed chitin-mannitol as a new excipient for oro-dispersible tablets. Mar. Drugs, 13(4), 1739, 2015.
5. Edwards J. et al.: Single dose dipyrone for acute postoperative pain. Cochrane Database Syst. Rev., 2010. doi:10.1002/14651858.CD003227. pub2.

6. Efentakis M., Vlachou M.: Evaluation of high molecular weight poly(oxyethylene) (Polyox) polymer: studies of flow properties and release rates of furosemide and captopril from controlled-release hard gelatin capsules. Pharm. Dev. Technol., 5(3), 339, 2000.

7. European Pharmacopoeia, $7^{\text {th }}$ ed. Strasbourg: Council of Europe, 2010.

8. Faqih A.M. et al.: Effect of moisture and magnesium stearate concentration on flow properties of cohesive granular materials. Int. J. Pharm., 336(2), 338, 2007.

9. Huber M. et al.: Metamizole-induced agranulocytosis revisited: results from the prospective Berlin case-control surveillance study. Eur. J. Clin. Pharmacol., 71(2), 219, 2015.

10. Jalil R., Ferdous A.J.: Effect of viscosity increasing agent and electrolyte concentration on the release rate of theophylline from a HPMC based sustained release capsules. Drug Dev. Ind. Pharm., 19(19), 2637, 1993.

11. Kołodziejczyk M.K., Kołodziejska J., Zgoda M.M.: Ibuprofen release preferences of medicinal products, the market share of excipients vermet of a polymer. Polim. Med., 40(4), 19, 2010.

12. Korzeniowska K., Jankowski J., Jabłecka A.: Nonsteroidal antiinflammatory drugs. Farm. Wspót., 3, 192, 2010.

13. Lahdenpää E., Niskanen M., Yliruusi J.: Crushing strength, disintegration time and weight variation of tablets compressed from three Avicelä PH grades and their mixtures. Eur. J. Pharm. Biopharm., 43, 315, 1997.

14. Luukkonen P. et al.: Rheological characterization of microcrystalline cellulose and silicified microcrystalline cellulose wet masses using a mixer torque rheometer. Int. J. Pharm., 188(2), 181, 1999.

15. Martínez-Martín P. et al.: Efficacy and safety of metamizol vs. acetylsalicylic acid in patients with moderate episodic tensiontype headache: a randomized, double-blind, placebo- and activecontrolled, multicentre study. Cephalalgia, 21(5), 604, 2001.

16. Murtada A.O., Abdelkarim M.A., Huyam A.M.: The effect of sodium starch glycolate concentration on physical effectiveness of chlorpheniramine tablets. Indian J. Pharm. Educ., 4(1), 47, 2013.

17. Nikolova I. et al.: Metamizole: A review profile of a well-known "forgotten" drug. Part I: Pharmaceutical and nonclinical profile. Biotechnol. Biotechnol. Equip., 26(6), 3329, 2012.

18. Nokhodchi A. et al.: The role of oral controlled release matrix tablets in drug delivery systems. Bioimpacts, 2(4), 175, 2012.

19. Overguard A.B.A. et al.: Patients' evaluation of shape, size, and color of solid dosage forms. Pharm. World Sci., 23(5), 185, 2001.

20. Patel R., Podczeck F.: Investigation of the effect of type and source of microcrystalline cellulose on capsule filling. Int. J. Pharm., 128, $123,1996$.

21. Shah R.B., Tawakkul M.A., Khan M.A.: Comparative evaluation of flow for pharmaceutical powders and granules. AAPS PharmSciTech., 9(1), 250, 2008.

22. Shlieout G., Arnold K., Müller G.: Powder and mechanical properties of microcrystalline cellulose with different degrees of polymerization. AAPS PharmSciTech., 3(2), 45, 2002.

23. Stegemann S. (2002). Hard gelatin capsules today -and tomorrow, $2^{\text {nd }}$ ed. Bornem: Capsugel Library.

24. Zgoda M.M.: Aktualnie stosowane substancje pomocnicze w technologii stałych doustnych środków farmaceutycznych. Farm. Pol., 59(17), 890, 2003.

25. Zhang P.Y. et al.: Preparation of poly (vinyl butyral) hollow fiber ultrafiltration membrane via wet-spinning method using PVP as additive. Desalination, 278, 186, 2011. 